\title{
PENGARUH MOTIVASI INTRINSIK, MOTIVASI EKSTRINSIK, LINGKUNGAN KERJA DAN BUDAYA ORGANISASI TERHADAP KINERJA KARYAWAN RUMAH SAKIT ISLAM BANJARNEGARA
}

\author{
Nur Wakhidah Lulu'ul Jannah \\ Universitas Muhammadiyah Purwokerto \\ Hermin Endratno \\ Universitas Muhammadiyah Purwokerto
}

\begin{abstract}
This research aimed to partially and simultaneously analyze: 1) intrinsic motivation towards the employees' performance, 2) extrinsic motivation towards the employees' performance, 3) working environment towards the employees' performance, 4) organization culture towards then employees' performance, 5) intrinsic motivation, extrinsic motivation, working environment and organization culture toward the employees' performance. It was a survey research. This research was conducted in Rumah Sakit Islam Banjarnegara with 100 employees as the respondents of the research are: 1) intrinsic motivation has no significant effect towards the employees' performance, 2) extrinsic motivation has no significant effect towards the employees' performance, 3) working environment has significant effect towards the employees' performance, 4) culture has significant effect towards the employees' performance, 5) intrinsic motivation, extrinsic motivation, working environment and organization culture has significabt effect toward the employees' performance.
\end{abstract}

Keywords: Intrinsic Motivation, Extrinsic Motivation, Working Environment, Organization Culture, Employees' Performance

\begin{abstract}
ABSTRAK
Penelitian ini memiliki tujuan untuk menganalisi secara parsial dan simultan: 1) motivasi intrinsik terhadap kinerja karyawan, 2) motivasi ekstrinsik terhadap kinerja karyawan, 3) lingkungan kerja terhadap kinerja karyawan, 4) budaya organisasi terhadap kinerja karyawan, 5) motivasi intrinsik, motivasi ekstrinsik, lingkungan kerja dan budaya organisasi terhadap kinerja karyawan. Jenis penelitian yang digunakan yaitu penelitian survei. Penelitian ini mengambil lokasi di Rumah Sakit Islam Banjarnegara, penelitian ini menggunakan 100 karyawan sebagai responden penelitiannya. Pembuktian hipotesis penelitian ini menggunakan regresi linier berganda. Hasil yang diperoleh dari penelitian ini adalah: 1) motivasi intrinsik tidak memiliki pengaruh signifikan terhadap kinerja, 2) motivasi ekstrinsik tidak memiliki pengaruh signifikan terhadap kinerja, 3) lingkungan kerja memiliki pengaruh signifikan terhadap kinerja, 4) budaya memiliki pengaruh signifikan terhadap kinerja, 5) motivasi intrinsik, motivasi ekstrinsik, lingkunga kerja dan budaya organisasi memiliki pengaruh signifikan terhadap kinerja.
\end{abstract}

Kata kunci: Motivasi intrinsik, Motivasi ekstrinsik, Lingkungan kerja, Budaya organisasi, Kinerja karyawan

\section{PENDAHULUAN}

Rumah sakit merupakan tempat untuk melakukan upaya meningkatkan kesehatan, mencegah dan menyembuhkan penyakit, serta memulihkan kesehatan. Pengelolahan unit usaha rumah sakit juga memiliki keunikan tersendiri karena selain sebagai unit bisnis, usaha rumah sakit juga memiliki misi sosial yang berperan penting dalam hal kesehatan masyarakat.

Berdasarkan Peraturan Menteri Kesehatan Republik Indonesia Nomor 147/MENKES/PER/2010 undang-undang No. 44 Tahun 2009 tentang rumah sakit dalam penetapan peraturan menteri kesehatan tentang perizinan rumah sakit. Dalam Permenkes (2010) UU No. 44 pasal, rumah sakit adalah institusi pelayanan kesehatan menyelenggarakan 
pelayanan kesehatan perorangan secara paripurna menyediakan pelayanan rawat inap, rawat jalan, dan gawat darurat.

Kabupaten Banjarnegara memiliki beberapa rumah sakit yaitu rumah sakit milik pemerintah dan rumah sakit swasta. Salah satu Rumah sakit swasta yang ada di Banjarnegara yaitu Rumah Sakit Islam Banjarnegara (RSIB), Rumah sakit ini merupakan rumah sakit islam swasta pertama yang ada di Banjarnegara. Rumah sakit ini merupakan salah satu Rumah Sakit swasta milik Perhimpunan Jama'ah Haji Kabupaten Banjarnegara (IPHI) yang di dirikan tanggal 1 Juni 1983 dan di kelola oleh Yayasan Rumah Sakit Islam Banjarnegara.

Keberadaannya merupakan bagian penting dari pelayanan publik yang bertujuan memberikan pelayanan sebaik-baiknya kepada masyarakat. Rumah sakit ini mempunyai visi menjadi rumah sakit terkemuka di Banjarnegara yang memberikan pelayanan islami bagi pasien. Pelayanan islami ini meliputi budaya organisasi yang ada di rumah sakit, inilah yang memberikan daya tarik tersendiri bagi masyarakat dan peneliti. Untuk meningkatkan kinerja karyawan yang ada di RSIB adalah dengan adanya motivasi yang dilakukan RSIB untuk meningkatkan kinerja karyawan adalah melalui pemberian bonus pada karyawan, memberikan ruang istirahat yang nyaman kepada karyawan.

Penelitian ini merupakan replikasi dari penelitian Pramadewi (2010). Hasilnya kinerja dipengaruh signifikan oleh budaya organisasi Penelitian ini berobjek di Rumah Sakit daerah Singingi sedangkan penelitian ini menggunakan objek di Rumah Sakit Islam Banjarnegara. Hal ini di perkuat oleh penelitian Widyanto (2014) bahwa budaya organisasi berpengaruh signifikan terhadap kinerja karyawan PT Bank Muamalat Indonesia Divisi Konsumer Area Cabang Surabaya. Dalam penelitian ini menambahkan variabel motivasi intrinsik, motivasi Ekstrinsik dan lingkungan kerja. Menurut hasil penelitian Fakhrian (2015) terdapat pengaruh signifikan motivasi intrinsik, motivasi ekstrinsik dan, komitmen organisasi terhadap kinerja karyawan pada bank BTN kantor cabang Malang, artinya semakin tinggi motivasi intrinsik dan motivasi ekstrinsik maka kinerja karyawan semakin baik. Sedangkan menurut hasil penelitian Anak (2012) pengaruh motivasi, lingkungan kerja, kompentensi, dan kompensasi terhadap kepuasan kerja dan kinerja pegawai di lingkungan kantor dinas pekerjaan umum provinsi Bali, bahwa lingkungan kerja berpengaruh signifikan terhadap kinerja. Tujuan penelitian ini untuk mengetahui konsistensi variabel penelitian dari penelitian terdahulu.

\section{TINJAUAN PUSTAKA}

\section{Kinerja Karyawan}

Prawirosentono (2009) kinerja seorang pegawai akan baik, jika pegawai mempunyai keahlian yang tinggi, kesediaan untuk bekerja, adanya imbalan/upah yang layak dan mempunyai harapan masa depan. Secara teoritis ada tiga kelompok variabel yang mempengaruhi kinerja individu, yaitu: variabel individu, variabel organisasi, dan variabel pisikologis. Kelompok variabel individu terdiri 12 dari variabel kemampuan dan keterampilan, latar belakang pribadi dan demografis. Prawirisentono (2009), yang dilihat dari indikator-indikator kinerja berikut:

a. Melaksanakan tugas sesuai dengan prosedur dan kebijakan pekerjaan.

b. Melaksanakan pekerjaaan tepat waktu.

c. Menguasai pengetahuan pekerjaan utama.

d. Kreatif dalam melaksanakan pekerjaaan

e. Mampu melaksakan pekerjaan utama.

\section{Motivasi Intrinsik}

Menurut Handoko (2001), jika di lihat atas dasar fungsinnya motivasi terbagi atas: motivasi intrinsik dan motivasi ekstrinsik. Motivasi intrinsik yaitu motivasi yang berfungsi tanpa adanya rangsangan dari luar, dalam diri individu sudah ada suatu dorongan untuk melakukan tindakan. Menurut Robbins (2006) variabel motivasi instrinsik diukur dengan indikator sebagai berikut : 
a. prestasi adalah pemberian kesempatan yang diberikan oleh perusahaan kepada karyawan yang berpotensi.

b. penghargaan adalah pemberian penghargaan kepada karyawan atas hasil kerja untuk mengembangkan diri.

c. tanggung jawab adalah tugas karyawan agar memahami dengan benar peran dan wewenang yang diberikan oleh perusahaan.

d. kesempatan maju dan berkembang adalah kesempatan karyawan untuk maju dan berkembang dalam hal pekerjaan.

\section{Motivasi Ekstrinsik}

Permana (2009) mengutip dari Nawawi menjelaskan motivasi ekstrinsik adalah pendorong kerja yang bersumber dari luar diri pekerja sebagai individu, berupa suatu kondisi yang mengharuskan melaksanakan pekerjaan secara maksimal. Sedangkan menurut Manullang (2001) dinyatakan bahwa jika perusahaan menyediakan kondisikondisi kerja, upah, tunjangan atau keselamatan kerja yang tidak mencukupi, maka ia akan mendapatkan kesulitan dalam menarik karyawan-karyawan yang baik dan perputaran dan kemangkiran akan meningkat. Adapun Indikator yang digunakan dalam mengukur motivasi ekstrinsik adalah :
a. Gaji yang sesuai dengan harapan.
b. Tunjangan jabatan berupa financial sudah memadai
c. Jaminan sosial yang memadai.
d. Pemberian bonus kerja yang memadai.
e. Tunjangan hari raya yang sesuai harapan

\section{Lingkungan Kerja}

Lingkungan kerja merupakan salah satu komponen terpenting dalam karyawan menyelesaikan pekerjaannya. Disini yang dimaksud dengan lingkungan kerja adalah segala sesuatu yang ada disekitar para pekerja yang dapat mempengaruhi dirinya dalam menjalankan tugas-tugas yang dibebankan. Menurut Nitisemito dalam Nurhasanah (2010), lingkungan kerja adalah segala sesuatu yang ada disekitar para pekerja yang dapat mempengaruhi dirinya dalam menjalanan tugas-tugas yang dibebankan. Misalnya: kebersihan, musik, dan lain-lain.Wursanto (2005), menyatakan yang menjadi indikator lingkungan kerja adalah:
a. Penerangan
b. Suhu udara
c. Suara bising
d. Penggunaan warna
e. Ruang gerak yang diperlukan
f. Keamanan kerja
g. Hubungan karyawan

\section{Budaya Organisasi}

Sebelum mendefinisikan pengertian budaya organisasi, perlu diketahui terlebih dahulu apa pengertian budaya dan apa pengertian organisasi. Dalam Kamus Besar Bahasa Indonesia, budaya berarti pikiran, akal budi, dan adat istiadat. Budaya juga berarti sesuatu yang sudah menjadi kebiasaan yang sudah sukar diubah. Dalam sumber lain, budaya berarti apa yang dilakukan orang dan apa arti tindakan mereka bagi diri mereka. Budaya juga merupakan gagasan, kepentingan, nilai-nilai dan sikap yang disumbangkan oleh kelompok. Adapun indikator budaya organisasi menurut Riani (2011) adalah:
a. Pernyataan filosofi formal, visi, misi.
b. Semboyan, bahasa, akronomi, dan perkataan.
c. Pembentukan peranan secara hati-hati.
d. Penhargaan eksplisit, simbol status, dan kriteris promosi.
e. Cerita, mitos, legenda suatu peristiwa dan orang-orang penting.
f. Aktivasi, proses atau hasil organisasi yang juga diperhatikan, diukur dan dikendalikan pemimpin.
g. Reaksi pemimpin terhadap insiden yaang kritis dan krisi organisasi.
h. Stuktur organisasi dan alirankerja 
i. Sistem dan prosedur organisasi.

j. Tujuan organisasi dan kriteria gabungan yang digunakan untuk rekruitmen, seleksi, pengembangan, promosi, pemberhentian, dan pengunduran diri pegawai

\section{KERANGKA PEMIKIRAN}

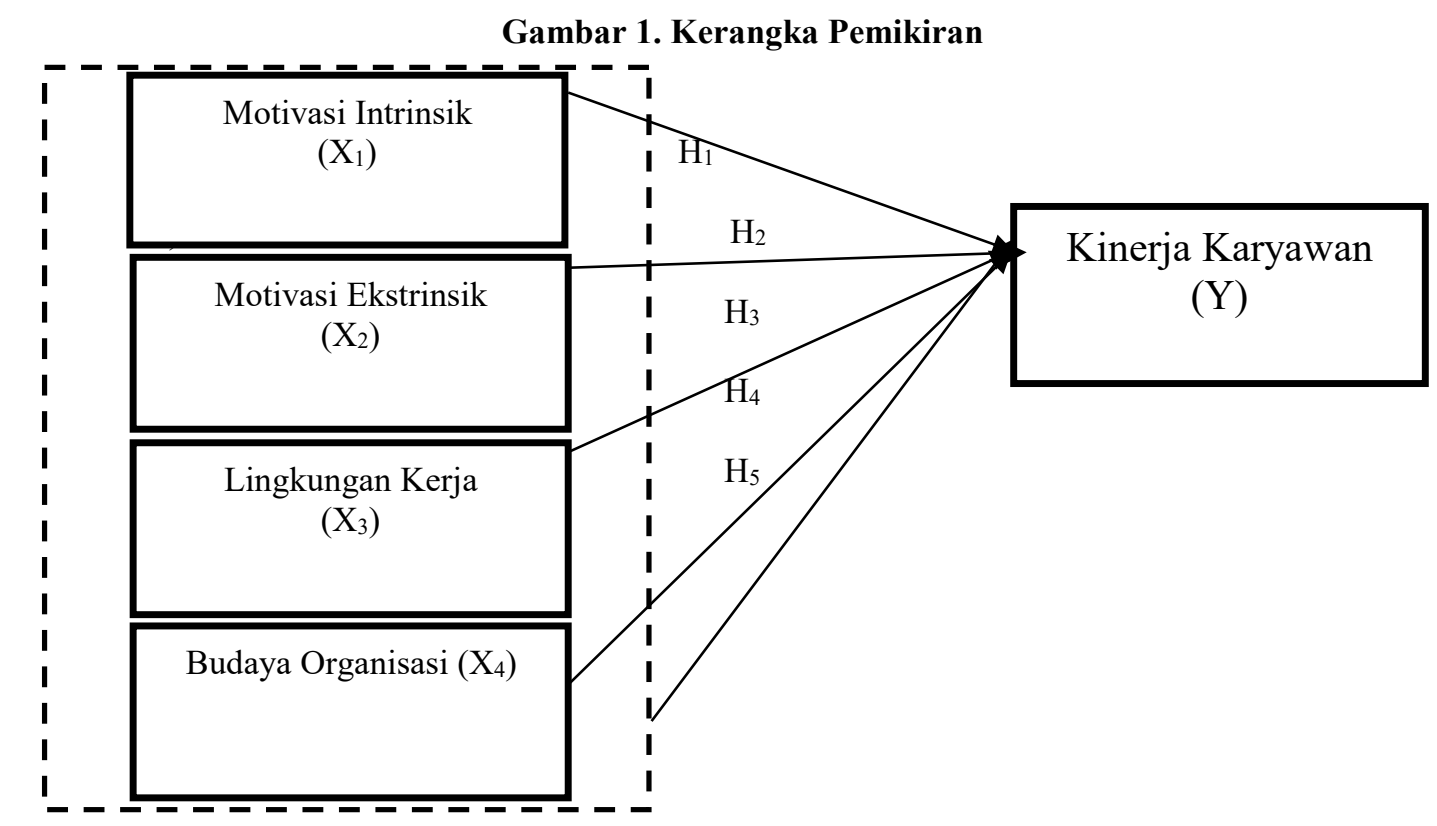

\section{HIPOTESIS}

Berdasarkan telaah teoritis dan telaah empiris, maka hipotesis dalam penelitian ini dirumuskan sebagai berikut :

$\mathrm{H}_{1}$ : motivasi intrinsik berpengaruh secara parsial terhadap kinerja karyawan.

$\mathrm{H}_{2}$ : motivasi ekstrinsik berpengaruh secara parsial terhadap kinerja karyawan.

$\mathrm{H}_{3}$ : lingkungan kerja berpengaruh secara parsial terhadap kinerja karyawan.

$\mathrm{H}_{4}$ : budaya organisasi berpengaruh secara parsial terhadap kinerja karyawan.

$\mathrm{H}_{5}$ : motivasi intrinsik, motivasi ekstrinsik, lingkungan kerja, dan budaya organisasi

berpengaruh secara simultan terhadap kinerja karyawan

\section{METODE PENELITIAN}

\section{Jenis Penelitian dan Tempat Penelitian}

Jenis penelitian ini menggunakan metode survei yaitu penelitian dari suatu pupulasi dengan menggunakan kuisioner sebagai alat pengumpul data responden. Bertempat di Rumah Sakit Islam Banjarnegara.

\section{Metode Analisis}

Untuk mengetahui apakah data layak atau tidak untuk diteliti maka diperlukan uji kelayakan data, agar kualitas instrumen dapat dipertanggungjawabkan pemakaiannya harus dapat dibuktikan dengan uji validitas dan reliabilitas. Uji validitas dan reliabilitas dilakukan terhadap 100 responden. Langkah-langkah uji validitas dan reliabilitas yang dilakukan adalah sebagai berikut :

\section{a. Uji kualitas data}

Kualitas data yang dihasilkan dari penggunaan instrumen penelitian dapat dievaluasi memlui uji reabilitas dan validitas artinya suatu penelitian akan menghasilkan kesimpulan yang bias jika datanya kurang reabel atau kurang valid. Sedangkan, kualitas data penelitian ditentukan kualitas instrumen yang digunakan untuk mengumpulkan data. 


\section{b. Uji Validitas}

Validitas menunjukkan sejauh mana suatu alat pengukur ( instrument) itu menunjukkan apa yang ingin diukur. Sebuah konsep tersusun dari beberapa komponen atau variabel.

\section{c. Uji Reliabilitas}

Menurut Sugiyono (2011), reliabilitas merupakan suatu konsistensi alat ukur dalam menghasilkan data, disebut konstan apabila data hasil pengukuran dengan alat yang sama dan berulang-ulang akan menghasilkan data yang relatif sama.

\section{d. Analisis Regresi Linier Ganda}

Analisis regresi yang digunakan adalah analisa regresi ganda, karena variabel bebasnya lebih dari satu. Analisa ini bertujuan untuk mengetahui ada atau tidaknya suatu hubungan antara variabel $\mathrm{X}_{1}$ (motivasi interinsik), $\mathrm{X}_{2}$ (motivasi ekstrinsik), $\mathrm{X}_{3}$ (lingkungan kerja), $\mathrm{X}_{4}$ (budaya organisasi) terhadap Y (kinerja).

\section{e. Uji Asumsi Klasik}

\section{1) Pengujian Normalitas}

Uji Normalitas data dimaksud untuk mengetahui apakah data yang digunakan dalam penelitian ini bersifat normal atau tidak. Pengujian normalitas data akan digunakan alat uji Kolmogorof Smirnov dengan menggunakan SPSS. Data mempunyai distribusi normal apabila mempunyai nilai signifikan $>0,05$ (Ghozali, 2005).

\section{2) Pengujian Multikolinieritas}

Uji Multikolinearitas dilakukan untuk mengetahui korelasi antar variabel-variabel independen yang digunakan dalam penelitian. Model regresi yang baik seharusnya tidak terjadi korelasi diantara variabel bebas. Dalam pengujian multikolinearitas akan digunakan angka Variance Infalntion Factor ( VIF ) dan Ttholerance. Sebuah model regresi akan bebas Multikoliniearitas apabila nilai VIF lebih kecil dari 10 (Ghozali, 2005)

\section{3) Pengujian Heteroskedasitas}

Uji ini dilakukan untuk mengetahui apakah varian dalam model regresi ketidaksamaan varian atau tidak. Gejala heteroskedastisitas terjadi sebagai akibat dari variasi residual yang sama untuk semua pengamatan.

\section{f. Uji Kelayakan Model}

\section{1) Uji F}

Untuk menguji pengaruh Motivasi Intrinsik, Motivasi Ekstrinsik, Lingkungan kerja dan Budaya Organisasi secara simultan berpengaruh positif terhadap kinerja karyawan pada Rumah Sakit Islam.

2) Uji t

Uji statistik t pada dasarnya menunjukkan seberapa jauh pengaruh satu variabel independen terhadap variabel dependen dengan menganggap variabel independen lainnya konstan (Ghozali, 2009).

\section{3) Koefisien Determinasi $\left(\mathbf{R}^{2}\right)$}

Koefisien determinasi $\left(R^{2}\right)$ pada intinya mengukur seberapa jauh kemampuan model dalam menerapkan variasi variabel dependen (Ghozali, 2011). 


\section{HASIL DAN PEMBAHASAN}

\section{Profil Responden}

Responden yang berpartisipasi dalam penelitian ini sebanyak 100 karyawan yang mempunyai karakteristik yang dapat dideskripsikan berdasarkan, umur, jenis kelamin, pendidikan akhir, lama bekerja, dan gaji. Deskripsi karakteristik responden dapat dijabarkan sebagai berikut:

a. Umur responden 21-25 sebanyak 34 orang, 26-30 sebanyak 45 orang, 31-35 sebanyak 6 orang, 36-40 sebanyak 6 orang, 41-45 sebanyak 4 orang, 46-50 sebanyak 3 orang, 51-55 sebanyak 2 orang.

b. Jenis kelamin, seluruh karyawan RSIB adalah laki-laki sebanyak 43 orang $(43,0 \%)$ dan perempuan berjumlah 57 orang $(57,0 \%)$.

c. Karyawan berpendidikan SMA sebanyak 28 orang, D3 sebanyak 56 orang, S1 sebanyak 16 orang, S2 sebanyak 2 orang.

d. Lama bekerja karyawan di RSIB 1-2 tahun sebanyak 12 orang, 2,1-3 tahun sebanyak 28 orang, 3,1-4 tahun sebanyak 16orang, $>5$ tahun sebanyak `45 orang.

e. Gaji di RSIB adalah 1-2juta sebanyak 33 orang, 2,1-3juta sebanyak 47 orang, 3,14 juta sebanyak 14 orang, $>5$ juta sebanyak 6 orang

\section{Uji validitas dan Reliabilitas}

Tabel 4.4 Motivasi Intrinsik

\begin{tabular}{|r|l|c|c|c|}
\hline No & Item Pertanyaan & r hitung & Nilai Signifikan & Keterangan \\
\hline 1 & mi_1 & 0.821 & 0,000 & Valid \\
\hline 2 & mi_2 & 0.684 & 0,000 & Valid \\
\hline 3 & mi_3 & 0.661 & 0,000 & Valid \\
\hline 4 & mi_4 & 0.669 & 0,000 & Valid \\
\hline 5 & mi_5 & 0.758 & 0,000 & Valid \\
\hline 6 & mi_6 & 0.788 & 0,000 & Valid \\
\hline
\end{tabular}

Sumber : Uji Validitas dan Realiabilitas

Tabel 4.5 Motivasi Ekstrinsik

\begin{tabular}{|r|l|c|c|c|}
\hline No & Item Pertanyaan & r hitung & Nilai Signifikan & Keterangan \\
\hline 1 & me 1 & 0.631 & 0,000 & Valid \\
\hline 2 & me_2 & 0.755 & 0,000 & Valid \\
\hline 3 & me 3 & 0.747 & 0,000 & Valid \\
\hline 4 & me_4 & 0.723 & 0,000 & Valid \\
\hline 5 & me_5 & 0.393 & 0,000 & Valid \\
\hline
\end{tabular}

Sumber : Uji Validitas dan Realiabilitas

Tabel 4.6 Lingkungan Kerja

\begin{tabular}{|r|l|c|c|c|}
\hline No & Item Pertanyaan & r hitung & Nilai Signifikan & Keterangan \\
\hline 1 & ling_1 & 0.644 & 0,000 & Valid \\
\hline 2 & Ling_2 & 0.542 & 0,000 & Valid \\
\hline 3 & ling_3 & 0.581 & 0,000 & Valid \\
\hline 4 & ling_4 & 0.61 & 0,000 & Valid \\
\hline 5 & ling 5 & 0.728 & 0,000 & Valid \\
\hline 6 & ling_6 & 0.476 & 0,000 & Valid \\
\hline 7 & ling_7 & 0.723 & 0,000 & Valid \\
\hline 8 & ling 8 & 0.507 & 0,000 & Valid \\
\hline
\end{tabular}

Sumber : Lampiran 4 Uji Validitas dan Realiabilitas

Tabel 4.7 Budaya Organisasi

\begin{tabular}{|r|l|c|c|c|}
\hline No & Item Pertanyaan & r hitung & Nilai Signifikan & Keterangan \\
\hline 1 & bud_1 & 0.48 & 0,000 & Valid \\
\hline 2 & bud_2 & 0.466 & 0,000 & Valid \\
\hline 3 & bud 3 & 0.484 & 0,000 & Valid \\
\hline 4 & bud_4 & 0.362 & 0,000 & Valid \\
\hline
\end{tabular}




\begin{tabular}{|r|l|c|c|c|}
5 & bud_5 & 0.54 & 0,000 & Valid \\
\hline 6 & bud_6 & 0.552 & 0,000 & Valid \\
\hline 7 & bud 7 & 0.508 & 0,000 & Valid \\
\hline 8 & bud 8 & 0.499 & 0,000 & Valid \\
\hline 9 & bud 9 & 0.48 & 0,000 & Valid \\
\hline 10 & bud 10 & 0.445 & 0,000 & Valid \\
\hline 11 & bud_11 & 0.536 & 0,000 & Valid \\
\hline 12 & bud_12 & 0.498 & 0,000 & Valid \\
\hline
\end{tabular}

Sumber : Uji Validitas dan Realiabilitas

Tabel 4.8 Kinerja Karyawan

\begin{tabular}{|c|l|c|c|c|}
\hline No & Item Pertanyaan & r hitung & Nilai Signifikan & Keterangan \\
\hline 1 & ki_1 & 0,673 & 0,000 & Valid \\
\hline 2 & ki_2 & 0.709 & 0,000 & Valid \\
\hline 3 & ki 3 & 0.725 & 0,000 & Valid \\
\hline 4 & ki_4 & 0.19 & 0,000 & Valid \\
\hline 5 & ki 5 & 0.71 & 0,000 & Valid \\
\hline
\end{tabular}

Sumber : Uji Validitas dan Realiabilitas

Berdasarkan tabel di atas, terlihat bahwa semua item pertanyaan variabel dapat dikatakan valid, karena nilai signifikasi $<0,05$.

Tabel 4.9 Uji Reliabilitas

\begin{tabular}{|l|c|c|}
\hline Variabel & $\begin{array}{c}\text { Cronbach' } \\
\text { Alpha }\end{array}$ & Keterangan \\
\hline Motivasi Intrinsik & 0,826 & Reliabel \\
\hline Motivasi Ekstrinsik & 0,664 & Reliabel \\
\hline Lingkungan Kerja & 0,749 & Reliabel \\
\hline Budaya Organisasi & 0,696 & Reliabel \\
\hline Kinerja Karyawan & 0,743 & Reliabel \\
\hline
\end{tabular}

Sumber : Lampiran 4 Uji Validitas dan Reabilitas

Berdasarkan tabel 4.9 Cronbach's Alpha dikatakan reliabel karena nilai Chornbach's Alpha pada seluruh variabel > 0,60 (Ghozali, 2009).

\section{Statistik Deskriptif}

Dapat dilihat pada tabel di bawah ini bahwa nilai rata-rata pertanyaan variabel motivasi intrinsik, motivasi ekstrinsik, lingkungan kerja, budaya organisasi dan kinerja karyawan $>3,5$ maka pertanyaan baik/set.

Tabel 4.10 Descriptive Statistics Descriptive Statistics

\begin{tabular}{|l|r|r|r|r|r|}
\hline & \multicolumn{1}{|c|}{$\mathrm{N}$} & Minimum & Maximum & Mean & Std. Deviation \\
\hline Motivasi Intrinsik & 100 & 2.33 & 5.00 & 3.6083 & .46984 \\
Motivasi Ekstrinsik & 100 & 2.40 & 5.00 & 3.6900 & .51747 \\
Lingkungan Kerja & 100 & 2.50 & 4.75 & 3.5700 & .47151 \\
Budaya Organisasi & 100 & 3.08 & 5.00 & 3.8675 & .30246 \\
Kinerja Kary & 100 & 3.00 & 5.00 & 3.9260 & .30439 \\
Valid N (listwise) & 100 & & & & \\
\hline
\end{tabular}

Sumber: Lampiran 5 Descriptive Statistic

\section{Uji Asumsi Klasik}

\section{a. Uji Normalitas}


Tabel 4.11 Hasil Uji Normalitas

One-Sample Kolmogorov-Smirnov Test

\begin{tabular}{|c|c|c|}
\hline & $\begin{array}{c}\text { Unstandardize } \\
\text { d Residual }\end{array}$ \\
\hline \multicolumn{2}{|l|}{$\mathrm{N}$} & 99 \\
\hline \multicolumn{2}{|c|}{ Normal Parameters ${ }^{\mathrm{a}}$ Mean } & .0000000 \\
\hline & Std. Deviation & .21411758 \\
\hline \multirow{3}{*}{$\begin{array}{l}\text { Most Extreme } \\
\text { Differences }\end{array}$} & Absolute & .055 \\
\hline & Positive & .055 \\
\hline & Negative & -.039 \\
\hline \multicolumn{2}{|c|}{ Kolmogorov-Smirnov Z } & .542 \\
\hline \multicolumn{2}{|c|}{ Asymp. Sig. (2-tailed) } & .930 \\
\hline
\end{tabular}

Sumber Lampiran 7 Uji Normalitas

Dengan melihat nilai asymp.sig dalam tabel 4.12 sebesar 0,930 maka dapat disimpulkan bahwa data penelitian telah terdistribusi normal, karena niali asymp.sig lebih dari 0,05 .

\section{b. Uji Multikolinearitas}

Tabel 4.12 Hasil Uji Multikolinearitas

Coefficients $^{\mathrm{a}}$

\begin{tabular}{|c|c|c|c|c|c|c|c|}
\hline \multirow[b]{2}{*}{ Model } & \multicolumn{2}{|c|}{$\begin{array}{c}\text { Unstandardized } \\
\text { Coefficients }\end{array}$} & \multirow{2}{*}{\begin{tabular}{|c}
$\begin{array}{c}\text { Standardiz } \\
\text { ed } \\
\text { Coefficient } \\
\text { s }\end{array}$ \\
Beta
\end{tabular}} & \multirow[b]{2}{*}{$\mathrm{T}$} & \multirow[b]{2}{*}{ Sig. } & \multicolumn{2}{|c|}{ Collinearity Statistics } \\
\hline & B & Std. Error & & & & Tolerance & VIF \\
\hline 1 (Constant) & 1.022 & .338 & & 3.022 & .003 & & \\
\hline rerata_mi & .057 & .047 & 087 & 1.194 & .236 & 982 & 1.018 \\
\hline rerata_me & .055 & .045 & .091 & 1.219 & .226 & .930 & 1.075 \\
\hline rerata_ling & -.094 & .052 & -.146 & -1.810 & .073 & .802 & 1.247 \\
\hline rerata_bud & .733 & .081 & .727 & 9.055 & .000 & .809 & 1.236 \\
\hline
\end{tabular}

a. Dependent Variable: rerata ki

Sumber Lampiran 8 Uji Multikolinearitas

Berdasarkan tabel 4.13 tersebut diketahui bahwa nilai VIF semua variabel $<10$, sehingga dapat disimpulkan bahwa model regersi terbebas dari multikolinearitas.

\section{c. Uji Heteroskedastisitas}


Tabel 4.13 Hasil Uji Heteroskedastisitas

Coefficients $^{\mathrm{a}}$

\begin{tabular}{|l|r|r|r|r|r|}
\hline & \multicolumn{2}{|c|}{$\begin{array}{c}\text { Unstandardized } \\
\text { Coefficients }\end{array}$} & \multicolumn{1}{c|}{$\begin{array}{c}\text { Standardized } \\
\text { Coefficients }\end{array}$} & \multirow{2}{*}{ T } & Sig. \\
\cline { 2 - 4 } Model & \multicolumn{1}{|c|}{$\mathrm{B}$} & Std. Error & Beta & \multicolumn{1}{c|}{ T } \\
\hline (Constant) & .368 & .201 & & 1.831 & .070 \\
Motivasi Intrinsik & -.033 & .028 & -.120 & -1.182 & .240 \\
Motivasi Ekstrinsik & .029 & .026 & .116 & 1.117 & .267 \\
Lingkungan Kerja & .012 & .031 & .043 & .380 & .705 \\
Budaya Organisasi & -.060 & .048 & -.138 & -1.232 & .221 \\
\hline
\end{tabular}

A. Dependent Variable: ABS_RES

Sumber lampiran 9 Uji Heteroskedasitas

Berdasarkan hasil uji glejser pada tabel 4.14 dikatakan nilai signifikkan semua variabel $>0,05$. Dengan demikian, dapat diartikkan bahwa model regresi terbebas dari heteroskedasitas karena nilai signifikan $>0,05$.

\section{Regresi Linear Berganda}

Tabel 4.14 Hasil Regresi Linear Berganda Coefficients $^{\mathbf{a}}$

\begin{tabular}{|c|c|c|c|c|c|}
\hline \multirow[b]{2}{*}{ Model } & \multicolumn{2}{|c|}{$\begin{array}{c}\text { Unstandardized } \\
\text { Coefficients }\end{array}$} & \multirow{2}{*}{$\begin{array}{c}\text { Standardized } \\
\text { Coefficients }\end{array}$} & \multirow[b]{2}{*}{$\mathrm{T}$} & \multirow[b]{2}{*}{ Sig. } \\
\hline & B & Std. Error & & & \\
\hline 1 (Constant) & 1.022 & .338 & & 3.022 & .003 \\
\hline Motivasi Intrinsik & .057 & .047 & .087 & 1.194 & .236 \\
\hline Motivasi Ekstrinsik & .055 & .045 & .091 & 1.219 & .226 \\
\hline Lingkungan Kerja & -.094 & .052 & -.146 & -1.810 & .073 \\
\hline Budaya Organisasi & .733 & .081 & .727 & 9.055 & .000 \\
\hline
\end{tabular}

a. Dependent Variable: KINERJA KARY

Berdasarkan tabel tersebut disusun persamaan regresi sebagai berikut :

$\mathrm{Y}=1.022+0,057 X_{1}+0,055 X_{2}+-0,094 X_{3}+0,733 X_{4}$

Adapun interpretasi dari persamaan tersebut adalah :

$\alpha=1,022$ artinya berdasarkan persamaan regresi tersebut dapat diketahui bahwa jika variabel independen tidak berubah maka kinerja karyawan sebesar 1,022 satuan.

$\beta_{1}=\quad 0,057$ artinya setiap terjadi peningkatan motivasi intrinsik satuan maka akan terjadi kenaikkan kinerja karyawan sebesar 0,057 satuan jika variabel independen tetap lain.

$\beta_{2}=\quad 0,055$ artinya setiap terjadi peningkatan motivasi ekstrinsik satuan maka akan terjadi kenaikkan kinerja karyawan sebesar 0,055 satuan jika variabel independen yang lain tetap.

$\beta_{3}=\quad-0,094$ artinya setiap terjadi peningkatan lingkungan kerja satu satuan maka akan terjadi penurunan kinerja karyawan sebesar 0,094 satuan jika variabel independen yang lain tetap.

$\beta_{4}=\quad 0,733$ artinya setiap terjadi peningkatan budaya organisasi satu satuan maka akan terjadi kenaikan kinerja karyawan sebesar 0,733 satuan jika variabel independen yang lain tetap. 


\section{Uji Kelayakan Model}

a. Uji Determinasi

Tabel 4.15 Adjusted $R^{2}$ Determinasi Model Summary

\begin{tabular}{|l|c|c|c|c|}
\hline Model & $\mathrm{R}$ & R Square & $\begin{array}{c}\text { Adjusted R } \\
\text { Square }\end{array}$ & \multicolumn{2}{|c|}{$\begin{array}{c}\text { Std. Error of the } \\
\text { Estimate }\end{array}$} \\
\hline 1 & $.714^{\mathrm{a}}$ & .510 & .489 & .21863 \\
\hline
\end{tabular}

a. Predictors: (Constant), rerata_bud, rerata_mi, Sumber : Adjusted $R^{2}$ rerata_me, rerata_ling

Nilai Adjusted $R^{2}$ sebesar 0,510 . Hal ini berarti variabel motivasi intrinsik, motivasi ekstrinsik, lingkungan kerja dan budaya organisasi menentukkan kinerja sebesar 48,9\% sedangkan sisanya 51,1\% dipengaruhi oleh faktor lain yang tidak diteliti dalam penelitian ini, contoh dari faktor yang tidak diteliti adalah variabel gaya kepemimpinan, pengembangan karir, stres kerja dan kompensasi.

b. Uji F

Dalam pengujian uji $\mathrm{F}$ bertujuan untuk menganalisis derajat signifikan hubungan variabel-variabel independen Motivasi Intrinsik $\left(\mathrm{X}_{1}\right)$, Motivasi Ekstrinsik $\left(\mathrm{X}_{2}\right)$, Lingkungan Kerja $\left(\mathrm{X}_{3}\right)$, Budaya Organisasi $\left(\mathrm{X}_{4}\right)$ secara bersama-sama berpengaruh terhadap variabel dependen Kinerja Karyawan (Y) menggunakan uji $\mathrm{F}$ pada tabel berikut:

Tabel 4.16 Hasil Uji F

ANOVA ${ }^{b}$

\begin{tabular}{|l|r|r|r|r|r|}
\hline Model & \multicolumn{1}{|c|}{$\begin{array}{c}\text { Sum of } \\
\text { Squares }\end{array}$} & Df & Mean Square & F & Sig. \\
\hline 1Regression & 4.674 & 4 & 1.168 & 24.447 & $.000^{\mathrm{a}}$ \\
Residual & 4.493 & 94 & .048 & & \\
Total & 9.167 & 98 & & & \\
\hline
\end{tabular}

a. Predictors: (Constant), rerata_bud, rerata_mi, rerata_me, rerata_ling

b. Dependent Variable: rerata_ki

Sumber : Uji F

c. Uji t

Uji statistik t pada dasarnya menunjukkan seberapa jauh pengaruh satu variabel independen terhadap variabel dependen dengan menganggap variabel independen lainnya konstan (Ghozali, 2011).

Tabel 4.17 Hasil Uji t

Coefficients $^{a}$

\begin{tabular}{|l|r|r|r|r|r|}
\hline \multirow{2}{*}{ Model } & \multicolumn{2}{|c|}{$\begin{array}{c}\text { Unstandardized } \\
\text { Coefficients }\end{array}$} & \multicolumn{2}{c|}{$\begin{array}{c}\text { Standardized } \\
\text { Coefficients }\end{array}$} & \\
\cline { 2 - 4 } & \multicolumn{1}{|c|}{$\mathrm{B}$} & Std. Error & Beta & \multicolumn{1}{c|}{$\mathrm{T}$} & \multicolumn{1}{c|}{ Sig. } \\
\hline 1 (Constant) & 1.022 & .338 & & 3.022 & .003 \\
Motivasi Intrinsik & .057 & .047 & .087 & 1.194 & .236 \\
Motivasi Ekstrinsik & .055 & .045 & .091 & 1.219 & .226 \\
Lingkungan Kerja & -.094 & .052 & -.146 & -1.810 & .073
\end{tabular}




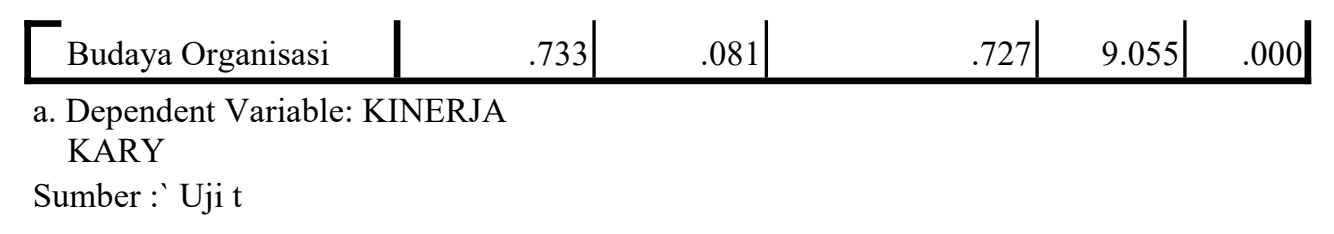

\section{Pembahasan}

Tabel 4.18 Hasil Penelitian

\begin{tabular}{|r|l|r|r|l|l|}
\hline \multicolumn{1}{|c|}{ No } & Variabel & \multicolumn{1}{l|}{$\mathrm{t}$ tabel } & \multicolumn{1}{c|}{ thitung } & signifikan & Keterangan \\
\hline 1 & Motivasi Intrinsik & 1,660 & 1,194 & 0,236 & Tidak Signifikan \\
\hline 2 & Motivasi Ekstrinsik & 1,660 & 1,219 & 0,226 & Tidak Signifikan \\
\hline 3 & Lingkungan kerja & 1,660 & $-1,810$ & 0,073 & Signifikan \\
\hline 4 & Budaya Organisasi & 1,660 & 9,055 & 0,000 & Signifikan \\
\hline
\end{tabular}

Sumber : Perbandingan $t_{\text {hitung }}$ dan $t_{\text {tabel }}$

Jadi kesimpulannya motivasi intrinsik mempunyai pengaruh positif dan signifikan terhadap kinerja karyawan, motivasi ekstrinsik berpengaruh positif terhadap kinerja karyawan, lingkungan kerja tidak berpengaruh terhadap kinerja karyawan, budaya organisasi berpengaruh positif dan signifikan terhadap kinerja karyawan.

Untuk mengetahui adanya pengaruh secara parsial dan simultan anatara variabel motivasi intrinsik, motivasi ekstrinsik, lingkungan kerja dan budaya organisasi di Rumah Sakit Islam Banjarnegara. Hasil penelitian ini menunjukkan bahwa asumsi klasik model regresi sudah terbebas dari permasalahan normalitas, multikolinieritas dan heteroskedasitas sehingga model regresi sudah tepat digunakan dalam pengujian hipotesis dalam penelitian ini.

\section{a. Pengaruh Motivasi Intrinsik terhadap Kinerja Karyawan}

Motivasi Intrinsik tidak berpengaruh signifikan terhadap kinerja karyawan Rumah Sakit Islam Banjarnegara. Penelitian ini sejalan dengan penelitian Sa'adiyah dan Endratno (2013) dengan judul Pengaruh Pengalaman Kerja, Motivasi Intrinsik, dan Kepuasaan Kerja Karyawan Terhadap Kinerja Karyawan Depo Pelita PT Pelita Satria Perkasa Sokaraja dengan hasil penelitian motivasi intrinsik tidak berpengaruh signifikan terhadap kinerja karyawan.

\section{b. Pengaruh Motivasi Ekstrinsik terhadap Kinerja Karyawan}

Motivasi ekstrinsik tidak berpengaruh signifikan terhadap kinerja karyawan Rumah Sakit Islam Banjarnegara. Penelitian ini sejalan dengan penelitian Lupita dan Azzuhri (2015) dengan judul Motivasi Intrinsik dan Ekstrinsik serta pengaruhnya terhadap Kinerja Karyawan (Studi pada Pekerjaan PT Pertamina RU V Balikpapan) dengan hasil motivasi ekstrinsik tidak berpengaruh secara nyata terhadap variabel kinerja karyawan.

c. Pengaruh Lingkungan Kerja Terhadap Kinerja Karyawan

Lingkungan kerja tidak berpengaruh signifikan terhadap kinerja karyawan RSIB. Penelitian ini sejalan dengan penelitian Dwi Anggoro (2013) dengan judul Pengaruh Displinan, Lingkungan Kerja dan Budaya Organisasi terhadap Kinerja Tenaga Kerja Pengajar dengan hasil lingkungan kerja tidak berpengaruh signifikan terhadap kinerja.

\section{d. Pengaruh Budaya Organisasi terhadap Kinerja Karyawan}

Budaya organisasi berpengaruh signifikan terhadap kinerja karyawan RSIB. Penelitian ini sejalan dengan penelitian dari Enrico Marawis (2013) dengan judul Kepemimpinan, Budaya Organisasi dan Motivasi Pengaruhnya terhadap Kinerja 
Karyawan pada PT Bank Tabungan Negara (Persero) Cabang Manado yang hasilnya Budaya organisasi berpengaruh signifikan terhadap kinerja karyawan.

\section{KESIMPULAN DAN SARAN}

1. Kesimpulan

Berdasarkan analisis yang telah dilakukan, maka di tarik beberapa kesimpulan antara lain:

1) Motivasi intrinsik tidak mempunyai pengaruh positif dan signifikan terhadap kinerja karyawan.

2) Motivasi ekstrinsik tidak mempunyai pengaruh positif dan signifikan terhadap kinerja karyawan.

3) Lingkungan kerja mempunyai pengaruh positif dan signifikan terhadap kinerja karyawan.

4) Budaya organisasi mempunyai pengaruh positif dan signifikan terhadap kinerja karyawan

\section{Saran}

1) RSIB untuk lebih meningkatkan motivasi intrinsik dengan cara memberi pelatihan motivasi supaya dapat meningkatkan kinerja karyawan.

2) RSIB untuk lebih meningkatkan motivasi ekstrinsik agar dapat meningkatkan kinerja karyawan. Misalnya dengan cara pemberian tunjangan jabatan yang diberikan RSIB bagi karyawannya.

3) Bagi RSIB untuk lebih meningkatkan lingkungan kerja supaya dapat meningkatkan kinerja karyawan, meskipun kondisi saat ini kinerja karyawan tidak terpengaruh dengan lingkungan kerja yang ada. Hal ini bisa terjadi dimungkinkan karena semangat kerja karyawan yang tinggi. Penelitian selanjutnya dapat meneliti faktor-faktor yang mempengaruhi semangat kerja karyawan.

4) RSIB mengimplementasikan budaya organisasi dalam hal pekerjaan 


\section{DAFTAR PUSTAKA}

Ghozali, Imam, 2011, Aplikasi Analisis Multivariate dengan program IBM SPSS 19 (edisi kelima). Semarang: Universitas Diponegoro.

Harza, Fakhrian, dkk. 2015. Pengaruh motivas nstrinsik, motivasi ekstrinsik dan komitmen organisasi terhadap kinerja kaeryawan pada Bank BTN kantor cabang Malang.

Marawis, E, 2013. Kepemimpinan Budaya organisasi dan Motivasi Pengaruhnya terhadap kinerja karyawan pada PT. Bank Tabungan Negara ( Persero) cabang Menado.

Manullang, M. 2001. Manajemen Sumber daya Manusia. Edisi 1 BBPS, Yogjakarta.

Prawirosentono, Suryadi, 2009. Manajemen Produktivitas. Jakarta: PT. Bumi Angkasa.

Robbins. Stephen P. dan Coulter, Mary, 2010. Manajemen (Edisi Kesepuluh) Jakarta: Erlangga.

Riani, Asri Laksmi, 2011. Budaya Organisasi. Cetakan Pertama, Edisi Pertama. Yogjakarta: Ghraha Ilmu.

Sugiyono, 2011. Metode Penelitian Kuantitatif Kuanlitatif dan R\&D. Bandung: Alfabeta.

Suprapto, J. 2000. Statistik Teori dan Aplikasi, edisi ke 6. Jakarta: Erlangga.

Wursanto, 2005. Dasar - dasar ilmu organisasi. Yogjakarta: Andi

Dasar-dasar ilmu organisasi. Yogjakarta: Andi. 